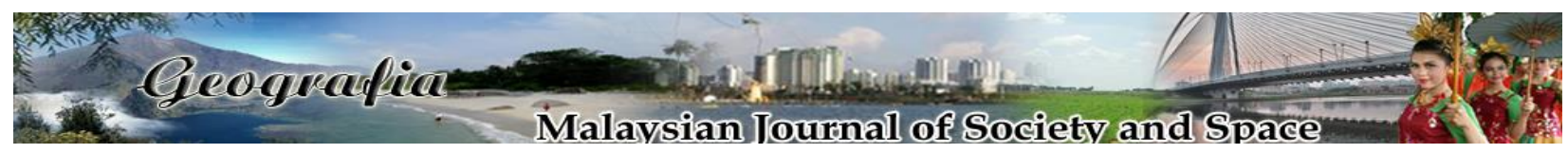

\title{
Masyarakat Orang Asli Jakun di Rompin, Pahang: Kajian terhadap pemuliharaan cerita lisan
}

\author{
Mohd Yuszaidy Mohd Yusoff ${ }^{1}$, Suffian Mansor ${ }^{2}$, Karim Harun ${ }^{1}$, Mohamad Rodzi Abd Razak ${ }^{2}$ \\ ${ }^{1}$ Pusat Kajian Bahasa, Kesusasteraan dan Kebudayaan Melayu, Fakulti Sains Sosial dan Kemanusiaan, \\ Universiti Kebangsaan Malaysia \\ ${ }^{2}$ Pusat Kajian Sejarah, Politik \& Hal Ehwal Antarabangsa, Fakulti Sains Sosial dan Kemanusiaan, \\ Universiti Kebangsaan Malaysia
}

Correspondence: Mohd Yuszaidy Mohd Yusof (yuszaidy@ukm.edu.my)

Received: 16 March 2021; Accepted: 10 May 2021; Published: 29 May 2021

\begin{abstract}
Abstrak
Kajian ini memfokuskan tentang pemuliharaan cerita lisan Orang Asli Jakun di Rompin, Pahang. Cerita lisan yang ada dalam kalangan masyarakat Orang Asli Jakun semakin berkurangan, beransur hilang dan diancam kepupusan. Hal ini akan memberi kesan terhadap kelangsungan cerita lisan sebagai sebahagian daripada tradisi lisan yang membentuk jati diri masyarakat Orang Asli Jakun. Oleh itu, kajian ini bertujuan untuk menganalisis pemuliharaan cerita lisan masyarakat Orang Asli Jakun dalam usaha untuk mengekalkan tradisi tersebut. Kajian ini berbentuk penyelidikan kualitatif menggunakan kaedah kajian lapangan dan temu bual separa struktur. Kaedah kajian lapangan dijalankan di Kampung Sungai Mok, Rompin, Pahang. Temu bual separa struktur dilakukan terhadap informan yang masih bergiat aktif dalam menuturkan cerita lisan. Kajian ini juga disokong oleh kajian perpustakaan yang menyediakan data sekunder berdasarkan kajian lepas. Kajian ini menggunakan teknik analisis tematik untuk menyaring data supaya memperoleh data yang betul dan sesuai. Hasil penemuan mendapati bilangan cerita lisan Orang Asli Jakun semakin berkurangan. Hasil kajian juga membuktikan bahawa aktiviti pemuliharaan ke atas cerita lisan itu dapat mengekalkan tradisi tersebut untuk dinikmati generasinya. Kelangsungan cerita lisan Orang Asli Jakun boleh bertahan dengan sokongan dan kerjasama daripada khalayak masyarakat mereka. Justeru, kajian ini dapat memberi manfaat terhadap usaha pemuliharaan cerita lisan agar dapat terus kekal dalam kalangan masyarakat Orang Asli Jakun. Sumbangan kajian ini juga amat bermakna terhadap kosa ilmu pengetahuan mengenai cerita lisan Orang Asli.
\end{abstract}

Kata kunci: Cerita lisan, Jakun, kearifan tempatan, kepupusan, Orang Asli, pemuliharaan. 


\title{
Jakun Orang Asli community in Rompin, Pahang: A study on the preservation of oral stories
}

\begin{abstract}
This study focuses on the conservation of Jakun Orang Asli oral stories in Rompin, Pahang. The oral stories that exist among the Jakun Orang Asli community are declining, gradually disappearing, and threatened with extinction. This will affect the continuity of oral stories as part of the oral traditions that shape the identity of the Jakun Orang Asli community. Therefore, this study aims to analyse the conservation of oral stories of the Jakun Orang Asli community to preserve the tradition. This study is a qualitative research using field research methods and semistructured interviews. The field research was conducted at Kampung Sungai Mok, Rompin, Pahang. The semi-structured interviews were conducted with informants who were still actively involved in telling oral stories. This study is also supported by library studies that provide secondary data based on past research. This study uses thematic analysis techniques to filter the data in order to obtain correct and appropriate data. The findings found that the number of oral stories of Jakun Orang Asli is decreasing. The results also prove that the conservation of oral stories can preserve the tradition for the enjoyment of its generation. The survival of the Jakun Orang Asli oral story can be sustained with the support and cooperation of their community audiences. Thus, this study can benefit the efforts to preserve oral stories in order to remain among the Jakun Orang Asli community. This study can provide a significant contribution to the vocabulary of knowledge about the oral stories of the Orang Asli.
\end{abstract}

Keywords: Oral story, Jakun, local wisdom, extinction, Orang Asli, conservation

\section{Pengenalan}

Masyarakat Orang Asli boleh dibahagikan kepada tiga kumpulan mengikut suku atau etnik yang mengamalkan sosiobudaya dan bentuk fizikal geografi. Masyarakat Orang Asli terdiri daripada Senoi, Negrito dan Melayu Proto. Senoi terdiri daripada sub etnik Temiar, Mah Meri, Jahut, Che Wong dan Semoq Beri yang majoriti mendiami Pantai Timur sehingga memasuki kawasan tengah Semenanjung Malaysia (Perak, Kelantan, Pahang dan Selangor). Suku Negrito pula terdiri daripada Kensiu, Kintaq, Jahai, Mendriq, Bateq dan Lanoh, suku kaum yang bertebaran di kawasan tengah Semenanjung Malaysia (Kelantan, Terengganu dan Pahang). Manakala, suku Melayu Proto terdiri daripada Temuan, Jakun, Semai, Orang Kuala, Orang Seletar dan Orang Kanaq. Suku Melayu Proto mendiami kawasan selatan Semenanjung Malaysia terutamanya di negeri Johor (Jabatan Kemajuan Orang Asli, 2020). Kajian ini merujuk kepada suku Jakun dalam kumpulan Melayu Proto atau Orang Ulu yang mendiami kawasan bukit, lembah, sungai dan gua. Etnik Jakun boleh dibahagi kepada dua sub etnik iaitu Jakun di hutan dan Jakun di laut (Orang Laut). Mereka antara kumpulan kedua etnik yang terbesar yang berjumlah 21,484 iaitu selepas etnik Semai daripada kumpulan Senoi (Jabatan Kemajuan Orang Asli, 2020). Suku Jakun kini masih mengekalkan corak kehidupan yang diwarisi dan mengamalkan kepercayaan animisme serta pantang larang dalam kelompok mereka (Kirk, 2015). Mereka juga masih menjalankan aktiviti mencari rotan dan akar kayu untuk pengubatan serta memburu binatang bersaiz kecil seperti 
landak, tupai, kancil dan pelanduk. Kehidupan mereka yang berhubungan rapat dengan dunia alam semula jadi telah memberi ilham kepada cerita lisan mereka.

Namun, cerita lisan yang mereka miliki semakin mengalami kehilangan kerana kurang mendapat sambutan daripada kalangan generasi muda. Masalah kurang sambutan terhadap cerita lisan kerana generasi muda telah banyak terdedah dengan perkembangan yang berlaku luar daripada lingkungan kehidupan masyarakat mereka. Penerimaan dan penggunaan teknologi hiburan moden seperti televisyen dan radio dalam masyarakat mereka secara meluas telah memberi tekanan kuat terhadap cerita lisan. Mereka telah beralih kepada bentuk hiburan yang baharu dan selari seperti mana dengan masyarakat kejiranan yang telah menyebabkan cerita lisan semakin tergugat dan terancam. Penerimaan komputer dan media sosial yang semakin meningkat dalam masyarakat juga telah memberi persaingan kepada kelangsungan cerita lisan. Generasi muda lebih mudah mendekati dan senang menggunakan komputer dan media sosial dalam kehidupan. Mereka boleh memperoleh pelbagai maklumat semasa dan hiburan secara lebih pantas. Perkembangan ini secara tidak langsung telah memberi kesan kurang baik kepada cerita lisan yang semakin hari mengalami kehilangan fungsi dan peranan dalam masyarakat sebagai alat hiburan dan penyampai nasihat.

\section{Kajian literatur}

Tinjauan kajian lalu mengenai pemuliharaan cerita lisan masyarakat Orang Asli masih kurang berbanding dengan kajian mengenai pembangunan ekonomi. Walaupun kajian mengenai pemuliharaan cerita lisan masyarakat Orang Asli adalah sukar untuk diperoleh dan dijadikan bahan rujukan, namun terdapat beberapa kajian yang berkait rapat dengan cerita lisan. Penelitian dan rujuk kepada kajian lalu dapat menghasilkan idea dan menimbulkan persoalan, kajian mengenai pemuliharaan cerita lisan dalam masyarakat Orang Asli kalangan suku Jakun dapat mengisikan kelompangan dan pengisian.

Kajian atau penulisan mengenai cerita lisan yang dimiliki oleh masyarakat Orang Asli amat kurang diberikan perhatian. Namun masih terdapat juga bahan-bahan penulisan yang berkait cerita lisan dalam kalangan masyarakat orang asli yang telah menjadi tumpuan kajian oleh pengkaji iaitu Ruhaiza Abu Bakar, Habibah Ahmad, Hamzah Jusoh, Mushrifah Idris dan Mohamad Kazar Razali (2017), kajian mengenai mitos dan legenda yang terdapat di Tasik Chini yang berkait rapat dengan masyarakat Jakun. Cerita lisan itu dapat memberi kesan yang baik dan positif dengan menjadikannya daya tarikan ke tasik itu. Kajian ini berusaha untuk mengangkat Tasik Chini sebagai pusat pelancongan maritim atau ekopelancongan. Selain itu, Shaiful Bahri Md Radzi, Hanapi Dollah dan Mohamad Luthfi Abdul Rahman (2016) mengenai pengumpulan cerita-cerita rakyat orang asli Jakun di Lembangan Endau-Rompin. Pengumpulan cerita rakyat ini adalah satu usaha untuk mendokumentasikan supaya dapat memberi perlindungan dan pengekalan cerita itu dalam masyarakat Jakun. Manakala, Mohamad Luthfi Abdul Rahman (2015), meneliti mengenai peranan penutur cerita rakyat masyarakat Melayu dan orang asli. Kajian ini memperlihatkan peranan dan fungsi secara perbandingan penglipur lara dan Pura Taman dalam komuniti masingmasing.

Namun begitu terdapat beberapa kajian lalu yang memberi tumpuan kepada cerita lisan masyarakat Melayu yang boleh dijadikan bahan rujukan dalam usaha pemuliharaan cerita lisan masyarakat Orang Asli Jakun. Siti Fatiemah Sa'at dan Jama'yah Zakaria (2013), meneliti mengenai masa depan cerita rakyat masyarakat Orang Asli Jakun. Kajian ini menjelaskan 
mengenai kebimbangan dan kerisauan terhadap masa depan cerita rakyat yang semakin mengalami semakin hilang dan pupus. Manakala, Mohd Firdaus Che Yaacob, Nasirin Abdillah, Muhammad Izani Ab. Ghani, Shahariah Norain Shaharuddin dan Siti Nur Anis Muhammad Apandi (2017), telah melakukan penelitian terhadap cerita-cerita rakyat Melayu mengenai moral positif yang boleh dijadikan panduan atau amalan kepada masyarakat. Kajian-kajian yang dilakukan didapati memberi tumpuan kepada aspek penelitian mengenai kepercayaan, kehidupan dan pendidikan. Kedua-dua kajian itu menjelaskan keperluan untuk pengekalan supaya cerita-cerita rakyat atau lisan pendidikan berada dalam kalangan masyarakat dan dijadikan sumber bahan pendidikan untuk generasi seterusnya. Perubahan masa dan kemodenan boleh menjejaskan warisan yang dimiliki sekiranya tidak diberikan perhatian sewajarnya terutamanya memastikan cerita-cerita rakyat berada dalam kehidupan generasi muda penuh pelbagai cabaran.

Begitu juga beberapa kajian mengenai pemuliharaan turut dirujuk bagi menjelaskan keperluan untuk menerangkan pemuliharaan terhadap cerita lisan masyarakat Orang Asli Jakun. Ahmad Shamsul Abd Aziz dan Nor Azlina Mohd Noor (2017) membuat penelitian berdasarkan kepada perundangan mengenai Akta Warisan Kebangsaan 2005 dalam usaha memberi perlindungan tetapi tidak mencukupi dan masih ada ruang untuk penambahbaikan ke atas akta itu. Mohd Yuszaidy (2018) menyatakan perlunya satu perundangan untuk memberi pengekalan kepada warisan tidak ketara. Mohd Yuszaidy dan Muammar Ghaddafi (2016) meneliti dan mendapati Akta 645 dan agensi penguat kuasa warisan telah memberi pemuliharaan sewajarnya daripada segi perlindungan akibat pembangunan fizikal, manusia dan cuaca supaya dapat dinikmati generasi seterusnya. Mohd Yuszaidy, Hanapi dan Ab Samad (2015) telah memberi cadangan dalam usaha untuk perlindungan kepada warisan budaya tidak ketara daripada hilang, pupus dan rosak. Mohd Yuszaidy, Hanapi dan Ab Samad (2013) telah meneliti mengenai usaha penggubalan Akta Warisan Kebangsaan 2005 oleh pihak kerajaan terhadap warisan ketara dan warisan tidak ketara telah memberi nafas baharu. Akta tersebut telah menyediakan peruntukan yang jelas terhadap setiap warisan ketara dan warisan tidak ketara melalui fasal-fasal peruntukan iaitu Senarai Warisan, Senarai Kebangsaan dan Daftar warisan Kebangsaan.

\section{Cerita Lisan dalam masyarakat Orang Asli Jakun}

Setiap masyarakat mempunyai cerita lisan yang tersendiri yang diilhamkan daripada kehidupan seharian dan alam persekitaran. Cerita lisan disampaikan oleh generasi tua kepada generasi muda mengenai nilai tauladan dan kearifan tempatan yang terdapat dalam masyarakat. Cerita lisan atau cerita rakyat yang terhasil dan terbentuk daripada falsafah pemikiran serta corak kehidupan seharian berlatarkan alam persekitaran menjadi satu keperluan dalam kehidupan (Ensiklopedia Sejarah dan Kebudayaan Melayu, 1999). Manakala, Mohd Taib Othman (1974) menjelaskan cerita lisan disampaikan melalui cara pengungkapan lisan dalam masyarakat dengan tokok tambah pencerita tetapi cerita lisan ini adalah milik bersama masyarakat itu sendiri. Perkara ini juga diketengahkan oleh Ismail Hamid (1987), beliau menjelaskan cerita lisan adalah lebih terawal berbanding dengan sistem tulisan. Begitu juga, cerita lisan telah berkembang secara meluas dalam masyarakat.

Penyampaian cerita ini dilakukan secara lisan oleh seorang individu yang berkemahiran dan menguasai cerita yang diperoleh melalui mimpi atau mempelajarinya. Dalam masyarakat Orang Asli Jakun, penyampaian cerita ini dilakukan secara lisan oleh pencerita. Halimah Hassan (1989) telah menegaskan mengenai penyampaian cerita lisan secara lisan dan bahawa cerita lisan atau rakyat adalah kesusasteraan yang telah dihidupkan secara lisan dan menggunakan 
pengantaraan pertuturan sebagai media. Beliau juga menjelaskan cerita lisan disampaikan melalui lafazan dari mulut ke mulut dan tidak bertulis. Cerita lisan berkembang dalam kalangan masyarakat pada peringkat awal sebagai hiburan kepada ahli masyarakat mereka. Mohd. Taib Othman (1988) pula menerangkan pertuturan secara lisan merupakan satu ekspresi budaya yang diterima serta diteruskan oleh masyarakat.

Begitu juga, pengucapan cerita lisan dalam kalangan masyarakat adalah milik bersama dan kepunyaan masyarakat itu sendiri yang disampaikan melalui secara pengucapan lisan pada masa dahulu. Perkembangan cerita lisan ini telah dipanjangkan dalam kalangan generasi ke satu generasi. Mohd Firdaus (2015) menjelaskan perkembangan cerita lisan masih mengekalkan elemen kandungannya. Secara keseluruhannya, cerita lisan adalah satu medium atau pengantara dalam memberi pendidikan dan pengetahuan kepada generasi muda mengenai nilai murni, minda, pemikiran, motivasi dan kehidupan harian dalam kalangan masyarakat. Mereka melihat mengenai pengajaran dan pembelajaran dalam membentuk sebahagian diri mereka dalam masyarakat. Bagi masyarakat, cerita lisan adalah sebahagian daripada kehidupan harian mereka yang membentuk jati diri dan falsafah pemikiran. Perkara ini selari dengan penjelasan mengenai cerita lisan yang merupakan penghasilan cerita lisan yang terpancar angan-angan dan harapan masyarakat terhadap sesuatu perkara dalam kehidupan masyarakat mereka (Bascom, 1965).

Masyarakat Orang Asli Jakun juga mempunyai cerita-cerita lisan yang dimiliki dan kepunyaan masyarakat mereka. Cerita lisan yang wujud berdasarkan kepada falsafah pemikiran dan kehidupan mereka yang berteraskan bukit bukau dan hutan belantara. Kebanyakan cerita lisan yang lahir dalam masyarakat mereka berkaitan rapat dengan persekitaran kehidupan dan alam semula jadi. Cerita lisan berkaitan rapat dengan masyarakat dalam usaha membentuk jati diri dan menyayangi kelompok mereka. Cerita-cerita lisan yang disampai bertemakan elemen sosial yang menceritakan tentang kehidupan dan bagaimana masyarakat mereka menghadapi cabaran yang boleh dijadikan pengajaran dan panduan kepada mereka. Hubungan dengan masyarakat luar lingkungan mereka juga dijadikan bahan cerita supaya dalam kalangan mereka dapat berinteraksi dengan baik terutamanya mengenai urusan bekerja dengan tekun dan berusaha. Kesemua plot cerita lisan yang dimiliki tidak dapat dipisahkan dengan peristiwa yang berlaku dalam kehidupan. Kadang-kadang peristiwa atau kejadian itu boleh menjadi bahan jenaka semasa penceritaan itu (Shaiful Bahri, Hanapi \& Mohamad Luthfi, 2016).

Secara umumnya, masyarakat Orang Asli Jakun semakin kurang menikmati cerita lisan terutamanya generasi muda. Mereka tidak berminat dan ada kalangan mereka juga tidak tahu tentang cerita lisan. Namun begitu, masyarakat Orang Asli Jakun masih memiliki koleksi cerita lisan ini antaranya Cerita Awang Miskin, Cerita Siti Munjadi, Cerita Pak Sehalus, Cerita Awang Buang, Cerita Kambing Buta dan Cerita Mamak Batin.

Kajian ini juga berpandukan kepada kerangka konseptual dalam usaha untuk menjelaskan mengenai cerita lisan masyarakat orang asli. Penggunaan kerangka konseptual supaya kajian ini dapat menjelaskan bagaimana untuk memulihara cerita lisan dalam kalangan masyarakat Orang Asli. Penerangan kerangka konseptual ini dapat menyatakan dan menyelesaikan isu mengenai pemuliharaan cerita lisan Orang Asli Jakun agar dapat dikekalkan dalam masyarakat mereka. Kerangka konseptual boleh dirujuk pada rajah 1 untuk menjelaskan penyelesaian isu tersebut. 


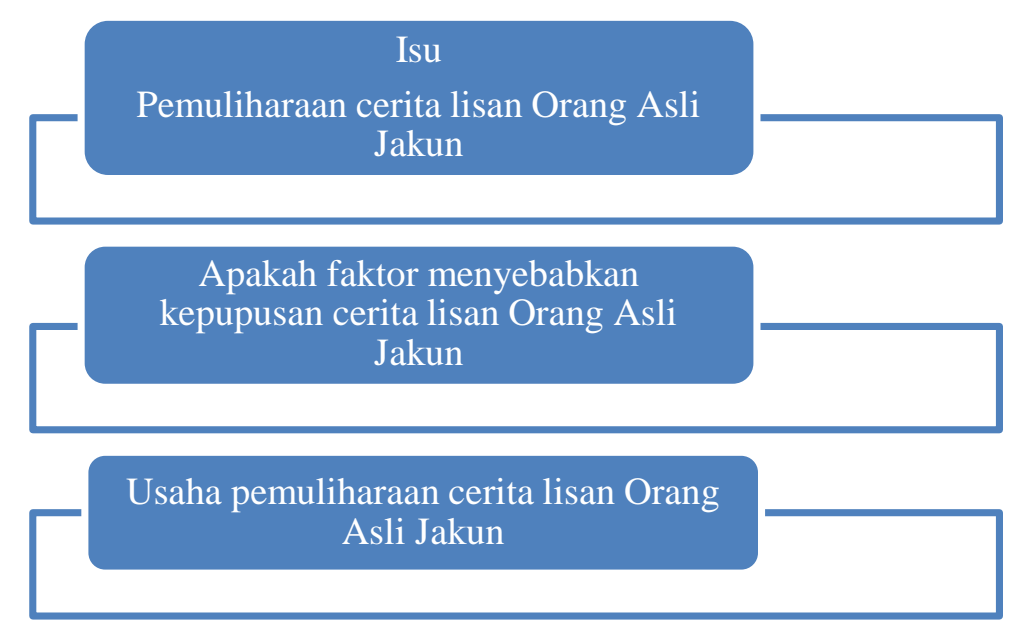

Rajah 1. Kerangka konseptual pemeliharaan cerita lisan Orang Asli Jakun

\section{Metodologi kajian}

Kajian ini menggunakan pendekatan kualitatif iaitu kajian lapangan. Kajian lapangan dilakukan di Kampung Sungai Mok, Rompin Pahang. Proses kajian lapangan dilakukan dengan menggunakan kaedah pemerhatian dengan sokongan kaedah temu bual separa struktur. Kajian pemerhatian untuk melihat persekitaran kehidupan mereka yang berlatarkan hutan belantara dan berbukit bukau. Pemerhatian juga dilakukan ke atas aktiviti harian mereka yang berhubung kait dengan hutan dan bukit untuk mendapat gambaran mengenai penghasilan cerita-cerita lisan mereka. Pemerhatian ini secara tidak langsung dapat mengumpulkan data-data yang rapat dengan bagaimana cerita lisan dapat dihasilkan dalam masyarakat mereka.

Temu bual separa struktur digunakan dalam pengumpulan data ini adalah berkaitan dengan kemampuan mereka untuk memberi tumpuan dan kefahaman mengenai soalan. Proses temu bual ini tidak begitu formal, sebaliknya dijalankan secara bersantai pada waktu petang selepas mereka selesai melakukan aktiviti harian. Soalan yang disediakan dalam bentuk terbuka dan mudah untuk difahami supaya mereka selesa untuk menjawab pertanyaan. Namun begitu, temu bual ini berlanjutan sehingga ke waktu malam bergantung kepada kesediaan mereka. Pertanyaan soalan sering berubah-ubah mengikut emosi mereka, ini dilakukan untuk mengelakkan mereka daripada timbul rasa tegang dan tekanan. Proses temu bual ini dilakukan terhadap informan yang berpengetahuan mengenai cerita lisan. Proses rakaman temu bual juga dijalankan secara serentak dengan temu bual dalam usaha untuk memperoleh data kajian. Kajian ini juga disokong dengan bahan sekunder daripada kajian kepustakaan untuk menambah maklumat. Data diperoleh itu menjalani proses analisis tematik untuk mendapat data yang benar dan sesuai dengan kajian ini.

\section{Dapatan kajian dan perbincangan}

Kajian ini mengenai pemuliharaan terhadap cerita lisan yang dimiliki masyarakat Orang Asli Jakun yang mendiami kawasan Rompin, Pahang. Pemuliharaan perlu dilakukan terhadap cerita lisan bagi mengelakkan ia mengalami kehilangan yang lebih serius. Hasil analisis yang dilakukan telah menemui faktor-faktor yang menyebabkan cerita lisan semakin mengalami kehilangan dan 
kepupusan dalam masyarakat. Cerita lisan amat bermakna dalam masyarakat Orang Asli Jakun yang merupakan sebagai pembuktian kearifan tempatan.

\section{Faktor menyebabkan kepupusan}

Masyarakat Orang Asli Jakun juga mengalami perkahwinan campuran dengan masyarakat kejiranan. Masyarakat yang telah bercampur dan berasimilasi yang lama dengan masyarakat luar terutamanya masyarakat Cina yang ramai mendiami persekitaran dunia luar mereka. Mereka berkahwin dan mengamalkan budaya luar terutamanya perempuan yang berkahwin dengan orang luar telah memberi kesan terhadap budaya mereka sendiri. Generasi muda yang lahir daripada perkahwinan itu tidak mengetahui atau mendengari cerita yang dimiliki oleh nenek moyang mereka. Mereka tidak diberikan pendedahan mengenai cerita lisan akibat banyak terpengaruh dengan hiburan dan aktiviti luar daripada lingkungan keturunan. Golongan muda daripada generasi itu perlu dibawa untuk penjelasan dan penerangan mengenai adat dan budaya terutamanya cerita lisan. Mereka perlu tahu mengenai tajuk dan kandungan cerita lisan supaya perkara ini boleh dilanjutkan kepada generasi seterusnya. Menurut Khalid Bin Pura, pihak keluarga terutamanya ibu bapa dan golongan tua dalam keluarga perlu memastikan pendedahan dengan memberitahu mengenai cerita-cerita lisan yang ada kepada mereka (temu bual, 2019). Keperluan ini amat penting supaya generasi muda hasil daripada perkahwinan campur tidak ketinggalan seperti mana dengan saudara mara dan rakan-rakan daripada kelompok yang sama. Kandungan cerita lisan amat bermakna dalam identiti mereka kerana hampir sebati dengan corak kehidupan mereka yang berlatarkan belantara dan bukit bukau. Masyarakat yang berinteraksi dengan alam semula jadi dalam membentuk jati diri dan kelangsungan kehidupan mereka.

Pencerita atau penutur cerita adalah median yang penting dalam menyampaikan cerita lisan. Mereka memperoleh cerita lisan melalui mimpi tetapi ada kalangan mereka berminat untuk mempelajari daripada pencerita yang lebih tua atau individu yang menguasai dan mahir dengan penceritaan. Dalam masyarakat Orang Asli, pencerita lahir daripada individu yang menerima kandungan cerita melalui mimpi dan ia perlu didedahkan serta diceritakan kepada khalayak ramai dalam kalangan masyarakat mereka. Keperluan penceritaan ini penting supaya cerita yang mengandungi elemen pengajaran dan nilai murni diterapkan dalam fikiran dan jiwa generasi muda. Namun begitu, pencerita semakin beransur-ansur tua dan perlu individu pengganti kepadanya. Menurut Khalid Bin Pura, kebolehan dan penguasaan jalan cerita atau kandungan cerita berkait dengan mimpi, memudahkan individu bercerita tanpa perlu menghafal atau mengingati secara berulangan (temu bual, 2019). Penguasaan luar biasa ini mengikut kepercayaan mereka, adalah individu yang terpilih melalui mimpi dan keadaan ini amat sukar mencari yang berbakat. Oleh itu, penggantian ini amat sukar untuk dilakukan apabila tiada individu hendak mempelajarinya kerana ini memerlukan jangka masa agak lama untuk menguasainya.

Pelbagai bentuk hiburan dalam dunia kemodenan telah menjejaskan permintaan terhadap cerita-cerita lisan dalam kalangan mereka terutamanya generasi moden. Mereka terdedah dengan hiburan seperti rancangan televisyen, siaran radio, tayangan filem, dan terkini media sosial yang dihasilkan melalui pelbagai aplikasi yang mudah dipraktis melalui peranti telefon bimbit dan komputer. Generasi muda juga didedahkan dengan pelbagai jenis sukan seperti bola sepak, sepak raga dan badminton yang boleh dimainkan bila-bila masa terutamanya pada waktu malam. Perkara ini menyebabkan kalangan mereka banyak menghabiskan masa di kawasan permainan dan tidak menghiraukan mengenai perkara berkait penceritaan cerita lisan. Situasi ini menyebabkan mereka sudah tidak berminat dan tidak lagi mengetahui cerita lisan yang dimiliki masyarakat mereka. Hal 
ini selari dengan pandangan Khalid Bin Pura, iaitu golongan muda perlu pendedahan dan menggalakkan mereka untuk turut serta dalam apa jua program berkaitan dengan kemasyarakatan serta pengisian cerita lisan perlu diterapkan (temu bual, 2019).

Sebelum ini ramai pencerita cerita lisan dalam kalangan masyarakat orang asli terdiri daripada golongan muda. Perubahan masa, mereka semakin meningkat tua dan uzur menyebabkan kalangan mereka sudah tidak aktif dan tiada pengganti. Begitu juga ada kalangan mereka sudah bersara daripada aktiviti bercerita. Perkembangan ini juga telah turut dialami pencerita cerita lisan suku Jakun yang semakin tua, kurang bertenaga dan uzur. Pada peringkat umur tua ini, beliau semakin kurang aktif bercerita. Beliau hanya bercerita apabila terdapat permintaan untuk bercerita. Walaupun semakin tua dan kurang bertenaga untuk bercerita, namun masih kuat daya ingatan untuk mengingati pelbagai cerita. Kekuatan ingatan ini kerana beliau menerima dan mempelajari cerita lisan ini melalui mimpi. Penerimaan secara mimpi memperkuatkan cerita lisan ini agar tidak berubah daripada segi jalan dan kandungan cerita. Cerita lisan itu sentiasa berlegar-legar dalam kepalanya tanpa perlu menghafal dan mempelajari secara lisan. Pencerita cerita lisan hanya bercerita di hadapan masyarakat tanpa menuntut sebarang bayaran kepada khalayak pendengar. Semasa penceritaan berlangsung, kebiasaannya pihak tuan rumah akan menyediakan juadah makanan. Bagi generasi muda dalam masyarakat Orang Asli Jakun, mereka tidak begitu berminat untuk mempelajari cerita lisan kerana ia satu pembelajaran yang susah dan tidak menarik serta sukar untuk menguasainya.

\section{Pemuliharaan cerita lisan}

Pelbagai cabaran dan perubahan yang berlaku dalam kehidupan seharian masyarakat Orang Asli Jakun telah memberi kesan kurang baik terhadap cerita lisan. Faktor-faktor kepupusan cerita lisan yang ditemui daripada hasil analisis dapat menjelaskan mengenai keperluan daripada segi pemuliharaan. Pemuliharaan terhadap cerita lisan dapat memberi sumbangan yang bermanfaat kepada masyarakat Orang Asli amnya generasi muda.

Cerita lisan masyarakat Orang Asli Jakun perlu diambil perhatian oleh pelbagai pihak bagi memastikan kelangsungannya. Oleh itu, kegiatan pemuliharaan terhadap cerita lisan masyarakat orang asli perlu dilakukan. Bagi memastikan pemuliharaan, perlu ada usaha kerjasama daripada pelbagai pihak berkepentingan. Kerjasama semua pihak berkepentingan akan memudah urusan untuk melakukan kerja pemuliharaan. Pelbagai pihak berkepentingan saling membantu mengatasi masalah mengenai cerita lisan Orang Asli Jakun. Kerjasama ini juga memudahkan untuk menyalurkan bantuan kewangan bagi menampung kos pemuliharaan. Selain itu, manfaat daripada kerja sama semua pihak berkepentingan dapat menyediakan platform untuk menjalankan aktiviti berkait dengan cerita lisan. Setiap pihak berkepentingan dapat mengadakan aktiviti penceritaan dengan perancangan yang lancar dan bersistematik.

Pemuliharaan cerita lisan masyarakat Orang Asli Jakun memerlukan satu usaha dan tindakan yang berkesan. Bagi memastikan cerita lisan masyarakat orang asli terpulihara, perlu ada satu bentuk pangkalan data digital. Pihak berkepentingan perlu membangun satu pangkalan data digital yang khusus mengenai cerita lisan. Pembangunan pangkalan data digital secara khusus mengenai pengumpulan dan penyimpanan akan lebih memudahkan cerita lisan itu berada di tempat yang khusus. Pengkalan data digital ini dapat memberi maklumat secara keseluruhan mengenai cerita lisan masyarakat orang asli. Adanya pangkalan data digital ini, cerita lisan dapat dilayari secara cepat dan mudah. Begitu juga, cerita lisan dapat dilayari oleh semua pihak tanpa ada sebarang halangan dan sekatan. Hal ini memudahkan cerita lisan masyarakat Orang Asli Jakun 
tersebar secara meluas tanpa sebarang batasan. Oleh itu, cerita lisan ini dapat dinikmati oleh semua masyarakat dan amnya generasi muda orang asli. Pembangunan pangkalan data digital secara tidak langsung dapat memulihara masa depan cerita lisan dalam masyarakat Orang Asli Jakun.

Pencarian bakat dalam kalangan masyarakat orang asli perlu dilakukan daripada peringkat awal lagi. Pencarian ini perlu untuk memastikan ada penggantian terhadap pencerita. Pihak kepentingan perlu melihat perlu ada pengganti kepada penutur atau pencerita cerita lisan. Pencarian bakat perlu dirancang terlebih dahulu. Perancangan awal ini penting supaya dapat memberi kesan sehingga berjaya. Proses pencarian bakat ini perlu memberi tumpuan pada peringkat awal kanak-kanak dalam kalangan mereka yang berpotensi. Mereka boleh dicari melalui pertandingan bercerita di peringkat sekolah rendah. Mereka yang terpilih perlu berlatih secara konsisten agar mereka mahir untuk bercerita. Pertandingan bercerita secara langsung membekalkan bakat muda pencerita walau tidak sehebat individu yang memperoleh cerita melalui mimpi. Usaha ini memerlukan sokongan daripada pelbagai pihak terutamanya daripada segi tenaga, masa dan kewangan.

Pemuliharaan cerita lisan masyarakat Orang Asli Jakun perlu juga memberi tumpuan terhadap penggiat atau pencerita. Pencerita cerita orang asli terdiri daripada individu yang telah berusia. Mereka perlu diberikan bantuan inisiatif kewangan untuk mengurang beban kos sara diri. Selain diberikan inisiatif daripada segi kewangan, mereka juga perlu memperoleh kemudahan perkhidmatan kesihatan seumur hidup. Pemberian bantuan inisiatif ini akan memberi galakan kepada mereka untuk meneruskan tradisi penceritaan lisan. Begitu juga, pihak berkepentingan iaitu Jabatan Hal Ehwal Orang Asli perlu mengadakan program latihan dengan memberi bantuan inisiatif daripada segi kewangan kepada generasi muda. Pemberian inisiatif galakan latihan akan menarik minat generasi muda untuk mempelajarinya. Keperluan ini penting, kerana untuk mempelajari cerita lisan memerlukan masa yang panjang dan perlu ada juga minat serta semangat yang kuat.

Pihak berkepentingan perlu menganjurkan satu karnival masyarakat pada setiap tahun dengan pengisian pelbagai aktiviti berkait masyarakat orang asli. Salah satu aktiviti dalam karnival ialah program merakyatkan cerita lisan dalam masyarakat orang asli. Program merakyatkan cerita lisan perlu diadakan bagi mendekatkan cerita lisan dengan generasi muda. Keperluan mengadakan program merakyatkan cerita lisan ini adalah suatu yang baik kerana mampu menarik golongan generasi muda. Program merakyatkan cerita lisan ini tidak hanya tertumpu kepada masyarakat Orang Asli Jakun, sebaliknya boleh diadakan program ini secara menyeluruh. Penglibatan keseluruhan masyarakat orang asli tanpa mengikut suku atau sub suku secara tidak langsung turut membantu kepada pemuliharaan cerita lisan. Karnival program merakyatkan cerita lisan ini dapat melestarikan cerita lisan dan juga kelangsungan warisan itu pada masa depan.

\section{Kesimpulan}

Keperluan pemuliharaan adalah suatu yang penting pada masa kini. Kebanyakan warisan khazanah yang dimiliki pelbagai masyarakat di negara ini semakin mengalami kerosakan, kepupusan dan kehilangan ditelan zaman. Warisan khazanah adalah satu yang bernilai tinggi. Warisan khazanah ini merupakan kearifan tempatan yang menjelaskan mengenai masyarakat terdahulu yang menghasilkan pelbagai budaya benda dan budaya bukan benda. Penghasilan kedua-dua elemen ini dalam masyarakat terdahulu telah menggambarkan keupayaan dan kemampuan mereka dalam 
meneruskan kelangsungan hidup. Penghasilan ini membuktikan masyarakat terdahulu mempunyai peradaban dan tamadun yang selari dengan keperluan hidup.

Penghasilan cerita lisan dalam masyarakat Orang Asli Jakun yang berdasarkan kepada kepercayaan dan persekitaran telah membentuk identiti. Cerita lisan yang berkait dengan mitos, legenda dan asal usul nama kampung atau tempat yang unik berbanding dengan kawasan lain telah menjadi warisan dan berkongsi bersama telah menunjukkan masyarakat orang asli adalah berbeza dengan suku kaum yang lain. Cerita lisan itu yang mengandungi pelbagai elemen nasihat dan kritikan masyarakat adalah untuk memberi kesedaran kepada masyarakat dan generasi muda mengenai keperluan hidup dalam keadaan baik dan damai. Keistimewaan dan kelebihan yang ada pada cerita lisan itu boleh menjadi satu yang boleh disumbangkan kepada masyarakat lain. Oleh itu, pemuliharaan terhadap cerita lisan masyarakat Orang Asli Jakun amat perlu bagi memastikan ia dapat dilindungi dan mengelakkan daripada kepupusan dan kehilangan.

\section{Penghargaan}

Kajian ini di bawah penyelidikan GPP-2020-026: Pembangunan model pemuliharaan cerita lisan Orang Asli Jakun, Rompin Pahang.

\section{Rujukan}

Ahmad Shamsul Abd Aziz, \& Nor Azlina Mohd Noor. (2017). Safeguarding intangible cultural heritage in Malaysia: A legal analysis on the National Heritage Act 2005. UMILC 2017, 9 UUM International Legal Conference. The European Proceedings of Social Behaviour, 841-848.

Bascom, W. (1965). The forms of folklore: Prose narratives. The Journal of American Folklore, 78(307), 3-20.

Ensiklopedia sejarah dan kebudayaan Melayu. (1999). Kuala Lumpur, Dewan Bahasa dan Pustaka.

Ismail Hamid. (1987). Budaya dan masyarakat Melayu. Kuala Lumpur, Dewan Bahasa dan Pustaka.

Jabatan Hal Ehwal Orang Asli. (2020). Statistik penduduk masyarakat Orang Asli mengikut negeri dan jantina. https://www.jakoa.gov.my/en/data-terbuka-sektor-awam/

Khalid Bin Pura. (2021). Cerita lisan masyarakat Orang Asli Jakun. Temu bual 23 Januari.

Kirk, E. (2015). Malaysia's original people: Past, present and future of the Orang Asli. Singapore, NUS Press.

Mohamad Luthfi Abdul Rahman. (2015). Awang Batil dan Pura Taman: Suatu perbandingan cerita penglipur lara Melayu dan Orang Asli. ATIKAN: Jurnal Kajian Pendidikan, 5(1), 49-64.

Mohd Firdaus Che Yaacob, \& Normaliza Abd Rahim. (2014). Cerita rakyat membentuk moral positif kanak-kanak melalui nilai murni. Journal of Business and Social Development, 2(2), 74-85.

Mohd Firdaus Che Yaacob, Nasirin Abdillah, Muhammad Izani Ab. Ghani, Shahariah Norain Shaharuddin, \& Siti Nur Anis Muhammad Apandi. (2017). Cerminan moral positif dalam cerita-cerita rakyat Melayu. International Journal of Language Education and Applied Linguistics (IJLEAL), 6, 35-44. 
Mohd Taib Osman. (1988). Kebudayaan Melayu dan beberapa persoalan. Kuala Lumpur, Dewan Bahasa dan Pustaka.

Mohd Yuszaidy Mohd Yusoff, \& Muammar Ghaddafi. (2016). Akta Warisan Kebangsaan 2005 (Akta 645): Penilaian daripada aspek perundangan dan penguat kuasa, Jurnal Melayu, 202223

Mohd Yuszaidy Mohd Yusoff, Hanapi Dollah, \& Ab Samad Kechot. (2013). Perlindungan harta warisan: Keberkesanan usaha pemuliharaan dan pemeliharaan dalam pembangunan negara. Geografia-Malaysian Journal of Society and Space, 9(2), 64-77.

Mohd Yuszaidy Mohd Yusoff. (2016). Pemuliharaan warisan budaya tidak ketara di Malaysia. Persidangan Antarabangsa Pengajian Alam Melayu 2016, Royal Asiatic Society, London.

Mohd Yuszaidy Mohd Yusoff. (2018). Pemuliharaan Warisan Budaya Melalui Perundangan Warisan dan Agensi Pelaksana. Jurnal Melayu, 17(2), 143-159.

Mohd. Taib Osman. (1976). Sastera rakyat: Tinjauan umum. Dlm. A. Bakar Hamid. (ed.), Diskusi sastera jilid 1: Sastera cerita. Kuala Lumpur, Dewan Bahasa dan Pustaka.

Ruhaiza Abu Bakar, Habibah Ahmad, Hamzah Jusoh, Mushrifah Idris, \& Mohamad Kazar Razali. (2017). Mitos dan legenda Tasik Chini sebagai produk pelancongan. Jurnal Wacana Sarjana, 1(1), 1-25.

Shaiful Bahri Md Radzi, Hanapi Dollah, \& Mohamad Luthfi Abdul Rahman. (2016). Cerita lisan Jakun: Dari Lembangan Endau-Rompin. Kuala Lumpur, Jabatan Kebudayaan dan Kesenian Negara.

Siti Fatiemah Sa'at, \& Jama'yah Zakaria. (2013). Masa depan cerita rakyat masyarakat Orang Asli Jakun. International Journal of the Malay World and Civilisation. 1(1), 83-88. 